was publishi:d and throughout that long period it has been the pre-eminent medium-sized volume in its subject. It was Manson's original intention to produce a volume 'of handy size and yet giving adequate information ... . for the exigencies of travel and of tropical life are, as a rule, incompatible with big volumes and large libraries.' This intention was carried out and has been kept in mind by its present editor, who is himself revising the book for the eighth time. His revision has been thorough and the material compressed into a little more than a thousand pages presents a balanced account of the principles and practice of tropical medicine. As a work of scholarship by a single author it can surely have seldom been surpassed.

Sufficient data is given of the pathological processes underlying the various diseases to enable the practitioner to understand them thoroughly while the practical aspects of differential diagnosis and treatment are given special prominence. In connection with the latter, there is a very valuable table of drugs occupying 18 pages of the text. In this the synonyms, composition, indications and dosages of the various substances are clearly stated. Regarding the former, an appendix covering 200 pages deals with medical zoology including medical protozoology, helminthology and entomology. It contains enough information to enable the practitioner to approach the various tropical diseases with understanding no matter how remotely situated from libraries he may be.

The publishers claim that the volume is almost unchallenged as the most authoritative and succinct account of the tropical diseases. It may fairly be claimed that they have not overstated their case.

A.W.W.

\section{ATOMIC MEDICINE}

Edited by Charles F. Behrens, M.D. Second edition. Pp. xiv +632 , with 100 illustrations. London: Baillière, Tindall \& Cox, Ltd. 1953. 845.

'The Atom Knocks at the Doctor's Door' is the sub-heading to the preface of this book. Whatever the personal reaction is to such a catchphrase, no one can deny that nuclear physics has advanced the science of medicine and at the same time created new hazards to health. Until a decade ago the scientific contributions were of academic interest only and the health hazards strictly localized in a few centres handling radium. Now, with the release of nuclear energy in chain reactions on an industrial scale, many thousands are faced with new occupational risks. At the same time isotopes have become available in adequate amounts for diagnosis, therapy and research. Should world war recur millions of people may be exposed to the effects of atomic bomb explosions.

An obvious need arose for a book on the medical aspects of nuclear physics and the first edition of 'Atomic Medicine ' in 1949 was well received. The progress since has necessitated considerable revision in the new edition, though the general plan remains the same. There are chapters on the fundamentals of nuclear physics and radiation biology, and on the methods of detecting and measuring radiation; chapters devoted to the pathology, diagnosis and therapy of radiation injuries and to the use of radioactive isotopes in medicine. In addition, there are separate sections devoted to the atomic bomb and to civil defence. New sections in this edition are on dosimetry and particle acceleration and the tables have been revised and extended.

There are 20 authors to this book, all American, and the majority are members of the Medical Corps of the United States Navy. As a result there is considerable overlap between chapters and a tendency to ignore work done in countries other than the United States. Each chapter, however, stands on its own as a review of its subject matter and copious references are given. The value of the work is as a first-class reference book and not as an account of atomic energy to be read from cover to cover.

It was disappointing not to find a clear explanation of the roentgen as a unit of radiation dosage. For the average doctor, conditioned to the dosage of drugs, it is a difficult concept to comprehend and little help has been given in this book. There are a number of misprints and minor errors and there is a great variation in the standard of the diagrams. Many are good, but some are very poorly drawn, with lettering by a shaky hand or an indifferent typewriter. This is not excusable in the second edition of a small book costing four guineas. There seemed to be no good reason for including the detailed decay schemes of the natural radioactive series.

These defects merely caused the reviewer some irritation and do not reduce the value of the work to any marked extent. To those dealing with the medical aspects of nuclear physics it is a most useful book.

S.R.

\section{DENTAL AND ORAL X-RAY DIAGNOSIS}

By A. C. W. Hutchison, D.D.S., M.D.S., F.D.S., F.R.S.E., Pp. xii + 524, with 946 illustrations. Edinburgh: E. \& S. Livingstone, Ltd. 1954. 75s.

At the beginning of the preface the author states his object in presenting this textbook is to provide, within reasonable limits, a survey of the present position of dental and oral $\mathrm{X}$-ray diagnosis and, what is more important, to emphasize the need for a still closer co-operation between the pathologist, the clinician and the radiologist. In this he has been highly successful and at the same time he has produced a book which is easy and pleasant to read, which is an excellent reference book and which, by the inclusion of clinical features, pathology and aetiology, should be of great value to those trying to acquire additional knowledge.

A wise and sound foundation is laid by presenting pictures of the normal in the first chapters. As the 
author says, variations are recognizable only when the normal is known.

$\mathrm{He}$ is to be congratulated on his choice and the quantity of material collected for the illustrations. With hardly a single exception, each is a beautiful specimen of the condition under consideration. The quality of reproduction is excellent; it is doubtful if it could be better.

The fact that some of the very rare conditions have had to be omitted in no way detracts from the value of this contribution to dental radiographic literature. Any reader who has studied and learned all that is included will be certain to recognize the difference shown in the rare condition and be sure of its unusual character. Reference can then be made to one of the works devoted to such matters.

Our impression is that undergraduate, graduate and postgraduate will all derive great help and benefit from this work, then after courses of study are over it will remain a valued book of reference, for, though treatment, aetiology and even nomenclature may change, radiographic appearances will remain the same.

\section{A PRACTICAL MANUAL OF DISEASES OF THE CHEST}

By Maurice Davidson, M.A., M.D., F.R.C.P. 4th Edition. Pp. $x+647$, with 255 illustrations. London: Geoffrey Cumberlege. 1954. 84s.

This is the fourth edition of the book first published in 1935 , and like its forerunners it is very well planned and beautifully written and produced.

It is a formidable undertaking to write a comprehensive textbook on diseases of the chest, including pulmonary tuberculosis, and in view of the great recent advances the task of bringing such a book entirely up to date is almost as heavy.

Much work has been done by the author and his assistant in this respect, but in the section dealing with the treatment of pulmonary tuberculosis chemotherapy is hardly mentioned until the end, and therefore is not discussed as an integral part of other active therapy or as an increasingly used form of treatment on its own.

Some other points of criticism may be classed as controversial, but it is difficult to see the justification for the continued use of the old terminology of the anatomy of the bronchial tree, or for the recommendation of 10 per cent. cocaine as a local anaesthetic for bronchography, especially without strict instructions concerning the maximum dose and the steps to be taken to deal with the alarming complications that occasionally occur with the use of this drug.

In the treatment of tension pneumothorax the importance of the mechanical problem has not been adequately stressed. Surely a sharp pneumothorax needle should not be left in situ in the chest, whereas the value and safety of self-retaining, blunt-ended needles used in association with continuous underwater drainage, with or without suction, should have been mentioned.

The stressing of these practical points is necessary, but does not alter the fact that this is a comprehensive book of quality and character. It is most enjoyable to read, and chest specialists and general physicians will find in it a fund of information.

\section{CIBA FOUNDATION SYMPOSIUM}

\section{Hypertension: Humoral and Neurogenic Factors}

Edited by G. E. W. Wolstenholme, O.B.E., M.A., M.B., B.Ch., and Margaret P. CAMERon, M.A., A.B.L.S. Pp. xiv +294 , illustrated. London: J. \& A. Churchill, Ltd. I954. 30s.

In this small volume are to be found the up-todate views of a great number of experts in the field of hypertension and its aetiology. It records the papers and discussions at a conference in July 1953 attended by more than 30 men of world-wides repute, from many countries, under the chairmano ship of Professor G. W. Pickering. In it one is privileged to be present at the often informal dison cussions between those who are the pioneers in this field. As a result there is a wealth of fascinating and absorbing matter in this book for those who wish to see where current research in the sphere of hypertension is leading.

The whole is so stimulating that it is perhaps wrong to treat it as the curate's egg. But the sections on phaeochromocytoma by Goldenberg and Peart, on the kidney in experimental hypertension by Floyer and on fluids and electrolytes by Ledingham were particularly notable. It is perhaps to be regretted that more distinction was not made by some speakers between hypertension and vascular disease, although even this error has its compensation in that the topic for discussion is thereby widened.

As a source of reference to modern research in cardiovascular physiology this book must be without rival. It will prove of great interest and value to all who wish to keep abreast of such subjects.

G.S.C.S. 